\title{
HGF mediated upregulation of lipocalin 2 regulates MMP9 through nuclear factor- $k B$ activation
}

\author{
SUNG AE KOH and KYUNG HEE LEE \\ Department of Hematology-Oncology, College of Medicine, Yeungnam University, \\ Namgu, Daegu 705-703, Republic of Korea
}

Received April 9, 2015; Accepted May 25, 2015

DOI: $10.3892 /$ or.2015.4189

\begin{abstract}
Lipocalin 2 (LCN2) is a member of lipocalin family that binds and transports a small lipophilic ligand, sharing a highly conserved tertiary structure and can be found as a monomer, homodimer, heterodimer with matrix metalloproteinase 9 (MMP9). The high molecule LCN2/ MMP9 complex was found in several cancer types. Yet, the mechanisms of regulation between LCN2 with MMP9 in tumorigenesis is unclear. The aims of the present study were to identify the function of LCN2 associated with MMP9 in gastric cancer growth and metastasis. First, we confirmed that the expression level of LCN2 and MMP9 was upregulated by hepatocyte growth factor (HGF). To identify the association pathway of HGF-induced LCN2, the cells were treated with PI3-kinase inhibitor (LY294002), or MEK inhibitor (PD098059), or p38 inhibitor (SB203580) and then analyzed using western blotting. The HGF-mediated LCN2 protein level was decreased with LY294002. Also, the HGF-mediated MMP9 was decreased with LY294002. The role for LCN2 with HGF mediated MMP9 was determined by knockdown of LCN2. LCN2-sh RNA cells showed a decreased level of HGF-mediated MMP9. The HGF-mediated LCN2 protein level was decreased with treatment of the $\mathrm{NF \kappa B}$ inhibitor. We confirmed the role of HGF-mediated LCN2. HGF-mediated cell proliferation and in vitro invasion was decreased in LCN2 knockdown cell. In conclusion, the present study showed that LCN2 upregulated MMP9 through PI3K/AKT/NFKB pathway in gastric cancer. LCN2 has a role in cell proliferation and cell invasion in gastric cancer, which may be a possible target for developing gastric cancer therapy.
\end{abstract}

Correspondence to: Professor Kyung Hee Lee, Department of Hemato-Oncology, College of Medicine, Yeungnam University, 170 Hyeonchung-ro, Namgu, Daegu 705-703, Republic of Korea E-mail:1khee@med.yu.ac.kr

Key words: Hepatocyte growth factor, lipocalin 2, matrix metalloproteinase 9, gastric cancer

\section{Introduction}

Lipocalin 2 (LCN2) is a member of lipocalin family that binds and transports a small lipophilic ligand, sharing a highly conserved tertiary structure (1). The binding ligands of lipocalin include retinoic acid, progesterone and prostaglandin. The function of LCN2 is known to be associated with cellular iron uptake, antibacterial activity and epithelial cell differentiation (2). Alpízar-Alpízar et al reported that LCN2 is upregulated in gastric mucosa infected with Helicobacter pylori known to be associated with gastric cancer. They proposed that the investigation of the connection of LCN2 and gastric cancer progression should be carried out (3).

Matrix metalloproteinase 9 (MMP9) is a member of MMPs that break down the basement membranes through the degradation of type IV collagen, exposing cryptic sites within matrix and allowing cancer cell invasion. Degradation of extracellular matrix (ECM) in tissue of the tumor is a principal process of cancer invasion and metastasis $(4,5)$. Particularly, MMP2 and MMP9 have been in focus recently in experimental models $(6,7)$. Some in vitro and in vivo studies showed that MMP level was possibly associated with cancer invasion and metastasis acting in colon cancer. Sier et al reported that the levels of MMP2 and MMP9 were enhanced in gastric cancer tissue compared to adjacent normal tissue (6), and the fact that polymorphism of alle of MMP promotor is significantly associated with gastric cancer invasion and metastasis, was reported (8).

Hepatocyte growth factor (HGF), produced primarily by mesenchymal cells, was known to have a role with a different activity of inducing epithelial cell dissociation. HGF has been shown to be an important factor of acting cancer cell invasion with interaction by tumor stromal tissue. We studied HGF-induced expressing genes in gastric cancer, and found that LCN2 also is expressed in NUGC3 and MKN28 cells treated with HGF using $17 \mathrm{~K}$ human cDNA microarrays.

LCN2 performs epithelial-to-mesenchymal transition via MMP9 dependent pathway. MMP9 is able to facilitate the extracellular matrix remodeling and bind the LCN2 with high affinity. LCN2 can be found as a monomer, homodimer, heterodimer with MMP9 and the binding of LCN2 to MMP9 promotes MMP9 activation and blocks the MMP9 autodegradation (9). This action restructures ECM persisting the action of invading the tissue, which facilitates metastasis (10). 
High molecule of LCN2 was detected in urine of breast cancer patients (11). In vitro data proved that LCN2 is principal factor of tumorigenesis and metastasis in breast cancer (12). The fact that in gastric cancer high level of LCN2 was detected compared to adjacent control tissue, and complexes of LCN2 and MMP9 are increased (13). However, the mechanisms of regulation of LCN2 in MMP9 activity or stabilization is not known.

In the present study, we examined the effect LCN2 knockdown on in vitro proliferation and invasiveness, and MMP9 regulation to identify the definite role of LCN2 in cancer proliferation and invasion in gastric cancer cell line. Also, we performed experiments to confirm the pathway facilitating the regulation MMP9 by LCN2.

\section{Materials and methods}

Cell culture. We used two human gastric cell lines in our experiments: NUGC3 and MKN28, which were obtained from the Korea Cell Line Bank. These cells were maintained on plastic in Dulbecco's modified Eagle's medium (DMEM) supplemented with $10 \%$ fetal bovine serum (FBS), $1 \mathrm{mM}$ sodium pyruvate, $0.1 \mathrm{mM}$ nonessential amino acids, $2 \mathrm{mM}$ L-glutamine, two-fold vitamin solution and $50 \mathrm{U} / \mathrm{ml}$ penicillin/streptomycin (Life Technologies, Inc., Gaithersburg, MD, USA). Unless otherwise noted, the cells were passaged and removed at $70-80 \%$ confluency.

Reagents and antibodies. Horseradish peroxidase-conjugated anti-mouse and anti-rabbit antibodies were purchased from Bio-Rad Laboratories (Philadelphia, PA, USA). Recombinant human HGF and pyrrolidine dithiocarbamate (PDTC) were purchased from R\&D Systems, Inc. (Minneapolis, MN, USA). LCN2 was purchased from Abnova (Taipei, Taiwan). MMP9 was purchased from Santa Cruz Biotechnology, Inc. (Santa Cruz, CA, USA). PD098059 was purchased from BIOMOL Research Laboratories, Inc. (Butler Pike, PA, USA). SB203580 and LY294002 were purchased from Calbiochem Inc. (San Diego, CA, USA). NFאB antibodies were purchased from Cell Signaling Technology (Beverly, MA, USA).

Semi-quantitative reverse transcription-polymerase chain reaction $(R T-P C R)$. Complementary DNA (cDNA) was synthesized from total RNA using M-MLV Reverse Transcriptase (Promega Corp., Madison, WI, USA) by the oligo(dT) priming method in a $10 \mu 1$ reaction mixture. PCR was performed in $10 \mu \mathrm{l}$ reaction volume containing $10 \mathrm{mM}$ Tris- $\mathrm{HCl} \mathrm{pH} 8.5$, $50 \mathrm{mM} \mathrm{KCl}, 1 \mu \mathrm{l}$ cDNA, $200 \mu \mathrm{M}$ dNTPs, $1 \mathrm{mM} \mathrm{MgSO}_{4}, 1 \mathrm{U}$ Platinum $P f x$ Taq polymerase and $2 \mu \mathrm{M}$ primers. The reactions were the initial denaturation at $95^{\circ} \mathrm{C}$ for $4 \mathrm{~min} ; 27$ cycles at $94^{\circ} \mathrm{C}$ for $15 \mathrm{sec}$, and $60^{\circ} \mathrm{C}$ for $15 \mathrm{sec}$, and $72^{\circ} \mathrm{C}$ for $30 \mathrm{sec}$; and the final extension at $72^{\circ} \mathrm{C}$ for $10 \mathrm{~min}$. The PCR products were separated on a $1.5 \%$ agarose gel containing ethidium bromide and visualized on a UV transilluminator.

cDNA microarray analysis. The cDNA microarray, containing a set of 17,448 sequence-verified human cDNA clones, was provided by GenomicTree, Inc. (Daejeon, Korea). cDNA microarray experiments were performed as described by
Yang et al (14). Briefly, total RNA $(100 \mu \mathrm{g})$ was reverse transcribed in the presence of Cy3-dUTP or Cy5-dUTP (25 mM stock; NEN Life Science Products, Boston, MA, USA) at $42^{\circ} \mathrm{C}$ for $2 \mathrm{~h}$. The labeled cDNA was then hybridized with the cDNA microarray at $65^{\circ} \mathrm{C}$ for $16 \mathrm{~h}$. The hybridized slides were washed, scanned with an Axon 4000B scanner, and analyzed using GenePix Pro 4.0 (both from Axon Instruments). Raw data were normalized and analyzed using GeneSpring 6.0 (Silicon Genetics). Genes were filtered according to their intensities in the control channel. When control channel values were below 80 the samples were considered as unreliable. Intensity-dependent normalization (LOWESS) was performed, where the ratio was reduced to the residual of LOWESS fit of the intensity vs. ratio curve. Average normalized ratios were calculated by dividing the averaged normalized signal channel intensity by the averaged normalized control channel intensity. The Welch ANOVA test was performed for P-values $\leq 0.1$ of 0.05 to identify genes differentially expressed samples. Correlation analysis was performed using Pearson's correlation (-1 to 1$)$. Spots showing changes of 2 -fold or more were considered significant.

Western blot analysis. Cells were harvested and incubated with a lysis buffer $[50 \mathrm{mM}$ Tris- $\mathrm{HCl}(\mathrm{pH} 8.0), 150 \mathrm{mM} \mathrm{NaCl}, 1 \mathrm{mM}$ EDTA, 1\% Triton X-100, 10\% glycerol, $1 \mathrm{mM}$ phenylmethylsulfonyl fluoride (PMSF), $1 \mathrm{mM}$ sodium vanadate and $5 \mathrm{mM}$ $\mathrm{NaF}$ ] with protease inhibitors and centrifuged at 15,000 rpm and $4^{\circ} \mathrm{C}$ for $10 \mathrm{~min}$. Proteins $(50 \mu \mathrm{g})$ were separated on $10 \%$ SDS-polyacrylamide gels and transferred to nitrocellulose membranes. The membranes were soaked with 5\% non-fat dried milk in TTBS [10 mM Tris- $\mathrm{HCl}(\mathrm{pH} 7.5), 150 \mathrm{mM} \mathrm{NaCl}$ and $0.05 \%$ Tween-20] for $30 \mathrm{~min}$ and then incubated overnight with a primary antibody at $4^{\circ} \mathrm{C}$. After washing 6 times with TTBS for $5 \mathrm{~min}$, the membranes were incubated with a horseradish peroxidase-conjugated secondary antibody for $90 \mathrm{~min}$ at $4^{\circ} \mathrm{C}$. The membranes were rinsed 3 times with TTBS for $30 \mathrm{~min}$ and antigen-antibody complexes was detected using the enhanced chemiluminescence detection system.

Zymography for MMP9. Culture supernatants were denatured in the absence of reducing agent and were electrophoresed in $10 \%$ polyacrylamide gel containing $0.1 \%(\mathrm{~W} / \mathrm{V})$ gelatin for MMP9. The gel was incubated at room temperature for $2 \mathrm{~h}$ in the presence of $2.5 \%$ Triton $\mathrm{X}-100$ and subsequently at $37^{\circ} \mathrm{C}$ overnight in a buffer containing $10 \mathrm{mM} \mathrm{CaCl}_{2}, 0.15 \mathrm{M}$ $\mathrm{NaCl}$ and $50 \mathrm{mM}$ Tris ( $\mathrm{pH} 7.5)$. The gel was then stained for protein with $0.25 \%$ Coomassie brilliant blue solution in methanol:acetic acid:water (4:1:5) and destained in the same solution without the dye; the enzyme activity was detected as the negatively-stained regions. Zymographic analyses were performed in at least 3 independent experiments.

3-(4,5-Dimethylthiazol-2-yl)-2,5-diphenyltetrazolium bromide (MTT) assay. Cells (1,500/well) were seeded in 96-well plates in DMEM supplemented with 5\% FBS and incubated for $24 \mathrm{~h}$. The cells were then serum-starved for $24 \mathrm{~h}$ and treated for $72 \mathrm{~h}$ with or without HGF $(10 \mathrm{ng} / \mathrm{ml})$. At the end of this incubation period, $50 \mu \mathrm{l}$ of $2 \mathrm{mg} / \mathrm{ml} \mathrm{MTT}$ solution was added and the cells were allowed to incubate for $3 \mathrm{~h}$ at $37^{\circ} \mathrm{C}$. The supernatant was carefully removed by aspiration, and the converted dye was 
A

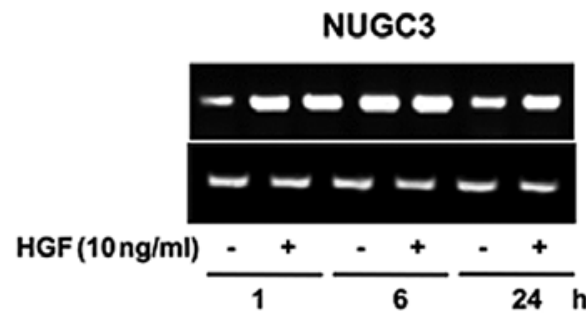

B

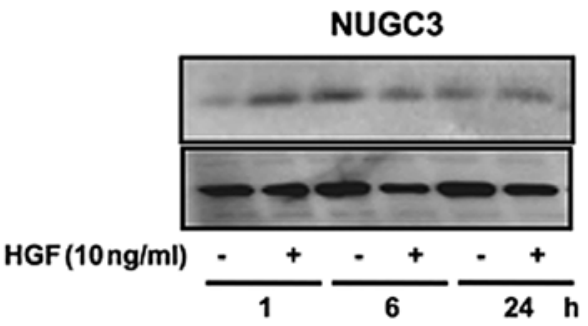

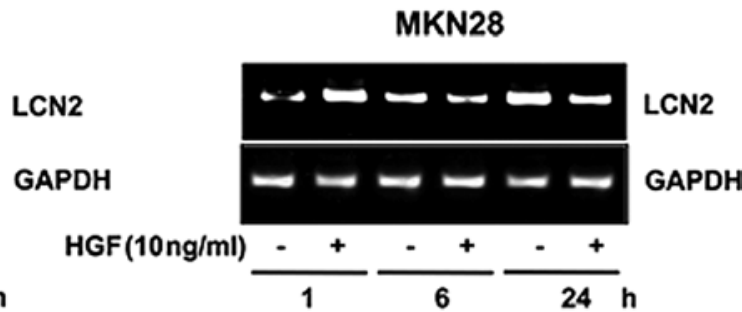

MKN28

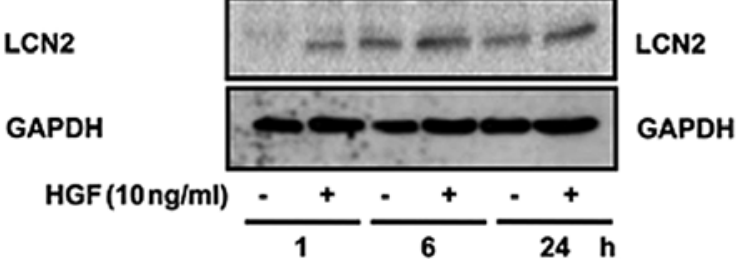

Figure 1. Effects of HGF on the expression level of LCN2. Cells were serum-starved for $24 \mathrm{~h}$, treated with/without HGF $10 \mathrm{ng} / \mathrm{ml}$ for the indicated times and harvested. The expression levels of LCN2 RNA and protein were confirmed by (A) reverse transcription-polymerase chain reaction and (B) western blot analysis. Representative data from 3 independent experiments are shown. HGF, hepatocyte growth factor; LCN2, lipocalin 2.

dissolved with $100 \mu \mathrm{l}$ DMSO. The plates were placed in a microplate shaker for $5 \mathrm{~min}$, and the absorbance was measured at $570 \mathrm{~nm}$ using a Bio-Rad multiscan plate reader.

Standard two chamber invasion assay. Control and transfected cells $\left(1 \times 10^{4}\right)$ were placed in the upper chamber of a Matrigel migration chamber with $0.8-\mu$ pores (Fisher Scientific, Houston, TX, USA) in media containing $5 \%$ FBS with or without HGF (10 ng/ml). After incubation for $48 \mathrm{~h}$, the cells were fixed and stained using the HEMA 3 stain set (Curtin Matheson Scientific, Inc., Houston, TX, USA) according to the manufacturer's instructions. The stained filter membrane was cut and placed on a glass slide. The migrated cells were counted under light microscopy (10 fields at x200 magnification).

LCN2 knockdown with short hairpin RNA. The human LCN2specific short hairpin RNA (shRNA) expression vector (LCN2-shRNA, RHS3979-201778075) containing LCN2targeted shRNA sequence (AAACCCAGGGCTGCCTTGGA AAAG) was purchased from Open Biosystems (Huntsville, AL, USA). NUGC3 and MKN28 cells were transfected with LCN2-shRNA using Lipofectamine (Life Technologies, Inc.). Clonal selection was conducted by culturing with puromycin $(25 \mu \mathrm{g} / \mathrm{ml})$ followed by serial dilution of the cells. Stable transfectant clones with low expression of the target genes were identified by western blot analysis.

Chromatin immunoprecipitation assay. The chromatin immunoprecipitation (ChIP) assay was carried out using the ChIP assay kit (Upstate Biotechnology, Waltham, MA, USA) following the manufacturer's directions. Briefly, cells were fixed with $1 \%$ formaldehyde at $37^{\circ} \mathrm{C}$ for $10 \mathrm{~min}$. Cells were washed twice with ice-cold $\mathrm{PBS}$ with protease inhibitors $(1 \mathrm{mM}$ PMSF, $1 \mathrm{mg} / \mathrm{ml}$ aprotinin and $1 \mathrm{mg} / \mathrm{ml}$ pepstatin A), scraped and pelleted by centrifugation at $4^{\circ} \mathrm{C}$. Cells were resuspended in a lysis buffer (1\% SDS, $10 \mathrm{mM}$ EDTA and $50 \mathrm{mM}$ Tris- $\mathrm{HCl}$, $\mathrm{pH}$ 8.1), incubated for $10 \mathrm{~min}$ on ice, and sonicated to shear
DNA. After sonication, lysate was centrifuged for $10 \mathrm{~min}$ at $13,000 \mathrm{rpm}$ at $4^{\circ} \mathrm{C}$. The supernatant was diluted in ChIP dilution buffer $(0.01 \%$ SDS, $1 \%$ Triton X-100, 2 mM EDTA, 16.7 mM Tris- $\mathrm{HCl}, \mathrm{pH} 8.1,167 \mathrm{mM} \mathrm{NaCl}$ and protease inhibitors). Primary antibodies were added and incubated overnight at $48^{\circ} \mathrm{C}$ with rotation. The immunocomplex was collected by protein $\mathrm{A} / \mathrm{G}$ agarose beads and washed with low salt washing buffer (0.1\% SDS, 1\% Triton X-100, 2 mM EDTA, $200 \mathrm{mM}$ Tris- $\mathrm{HCl}, \mathrm{pH} 8.1$ and $150 \mathrm{mM} \mathrm{NaCl})$, high-salt buffer $(0.1 \%$ SDS, 1\% Triton X-100, 2 mM EDTA, $200 \mathrm{mM}$ Tris- $\mathrm{HCl}$, $\mathrm{pH} 8.1$ and $500 \mathrm{mM} \mathrm{NaCl}), \mathrm{LiCl}$ washing buffer $(0.25 \mathrm{M} \mathrm{LiCl}$, $1 \%$ NP40, $1 \%$ deoxycolate, $1 \mathrm{mM}$ EDTA and $10 \mathrm{mM}$ Tris- $\mathrm{HCl}$, $\mathrm{pH} 8.1)$, and finally $1 \mathrm{TE}$ buffer $(10 \mathrm{mM}$ Tris- $\mathrm{HCl}$ and $1 \mathrm{mM}$ EDTA, pH 8.0). Then, the immunocomplex was eluted by the elution buffer ( $1 \%$ SDS, $0.1 \mathrm{M} \mathrm{NaHCO}_{3}$ and $200 \mathrm{mM} \mathrm{NaCl}$ ) and the crosslinks were reversed by heating at $65^{\circ} \mathrm{C}$ for $4 \mathrm{~h}$. After reaction, the samples were adjusted to $10 \mathrm{mM}$ EDTA, $20 \mathrm{mM}$ Tris- $\mathrm{HCl}, \mathrm{pH} 6.5$ and $40 \mathrm{mg} / \mathrm{ml}$ proteinase $\mathrm{K}$, and incubated at $45^{\circ} \mathrm{C}$ for $1 \mathrm{~h}$. DNA was recovered and was subjected to PCR amplification of the LCN2 promoter region, the primers were: 5'-gacagctcttccggctcacag-3' (forward) and 5'-cgctgtggt ggctgctgggec-3' (reverse).

Statistical analysis. Values are expressed as means \pm SD. The Student's t-test was employed for the analyses. A P-value of $<0.05$ was considered to indicate a statistically significant result.

\section{Results}

Upregulation of LCN2 level after treatment with HGF. To investigate the upregulation of the LCN2 gene, western blotting and RT-PCR analysis were performed. RT-PCR showed that the expression level of LCN2 mRNA was increased by treatment with HGF (Fig. 1A). The LCN2 protein level was increased after treatment with HGF, confirmed by western blot analysis (Fig. 1B). 
A

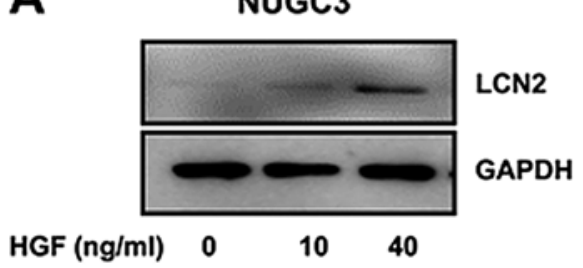

B

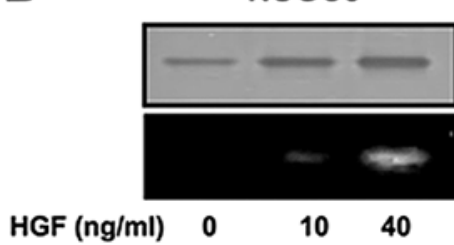

MKN28

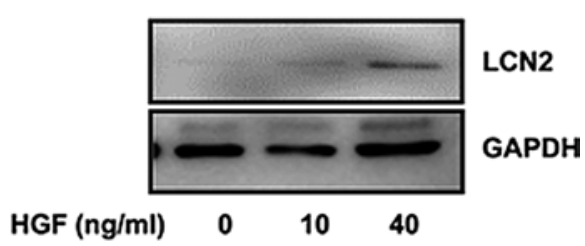

MKN28

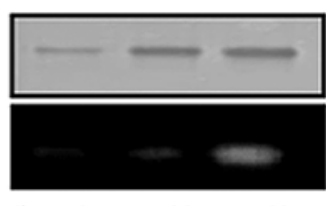

40
MMP9

MMP9

Figure 2. Expression of LCN2 and MMP9 is HGF dose-dependent. Serum-starved cells were treated with HGF 0, 10 and 40 ng/ml for $1 \mathrm{~h}$ and harvested. (A) The expression levels of LCN2 and MMP9 were confirmed by western blotting. (B) The MMP9 secreted in media was analyzed by western blotting and zymography. Representative data from 3 independent experiments are shown. LCN2, lipocalin 2; MMP9, matrix metalloproteinase 9; HGF, hepatocyte growth factor.
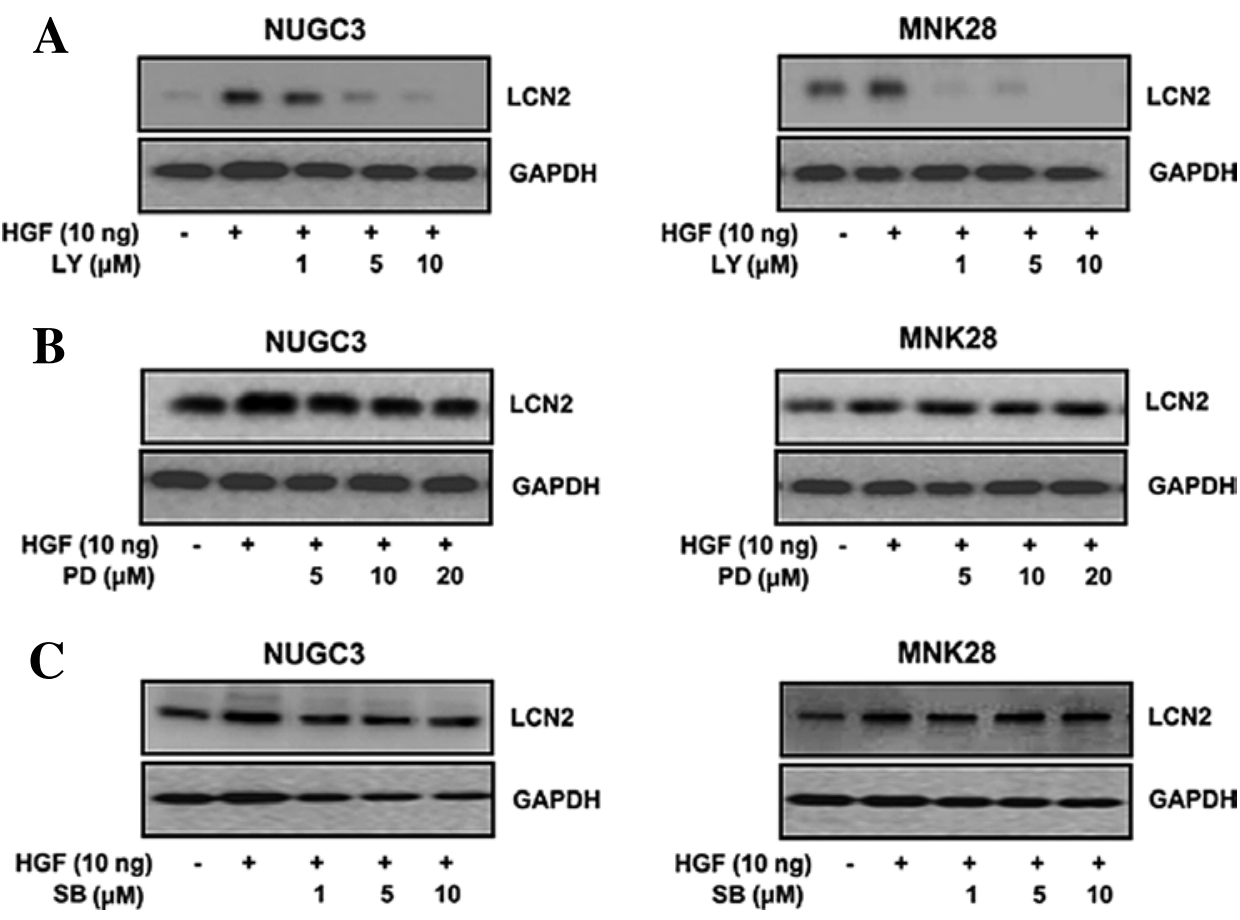

Figure 3. Effects of LY, PD and SB on the LCN2 expression. The cells (1x10\% with or without (A) LY, (B) PD, (C) SB at various doses for $1 \mathrm{~h}$ prior to incubation with or without $10 \mathrm{ng} / \mathrm{ml}$ of HGF and harvested. The LCN2 expression was analyzed by western blotting. Representative data from 3 independent experiments are shown. LCN2, lipocalin 2.

Upregulation of LCN2 and MMP9 level after treatment with $H G F$. We also tested the LCN2 protein level in HGF treatment in a dose-dependent manner confirmed by western blot analysis. The expression level of LCN2 protein was increased with increasing concentration of $\operatorname{HGF}(0,10$ and $40 \mathrm{ng}$ / ml) (Fig. 2A).

It is well known that MMP9 is associated with cancer invasion induced by HGF. To validate the MMP9 protein level in HGF treatment, western blotting and zymogram analysis were performed. The expression level of MMP9 protein was increased dose-dependently by $\operatorname{HGF}(0,10$ and $40 \mathrm{ng} / \mathrm{ml}$ ) (Fig. 2B).
Effects of LY294002, PD098059 and SB203580 on LCN2 expression. To identify whether or not PI3-kinase, ERK and MAPK activation was associated with HGF-induced LCN2, the cells were treated with PI3-kinase inhibitor (LY294002), or MEK inhibitor (PD098059), or p38 inhibitor (SB203580) and then analyzed by western blotting. The HGF-mediated LCN2 protein level was decreased with LY294002 (Fig. 3A). Yet, treatment with PD098059 (Fig. 3B) and SB203580 (Fig. 3C) showed no change in LCN2 expression in either NUGC3 and MNK28 cell lines (Fig. 3). These results suggested that HGF-mediated LCN2 is regulated by PI3-kinase, not by ERK or p38. 


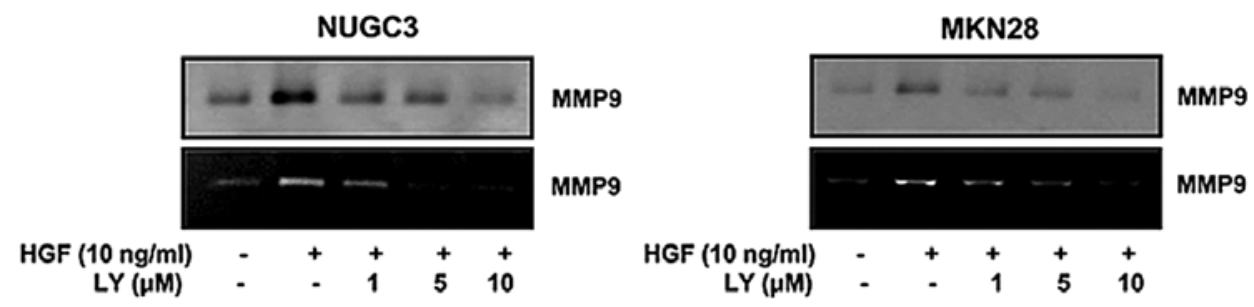

Figure 4. Effects of LY on MMP9 expression. The cells (1x10\% without LY at various doses for $1 \mathrm{~h}$ prior to incubation with or without $10 \mathrm{ng} / \mathrm{ml}$ of HGF for $48 \mathrm{~h}$, and harvested. The MMP9 secreted in media was analyzed by western blotting and by zymography. Representative data from 3 independent experiments are shown. HGF, hepatocyte growth factor; MMP9, matrix metalloproteinase 9 .

A

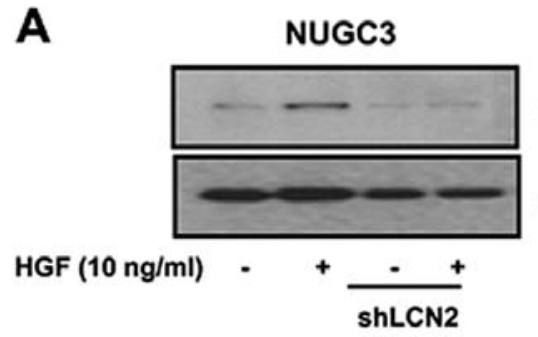

B

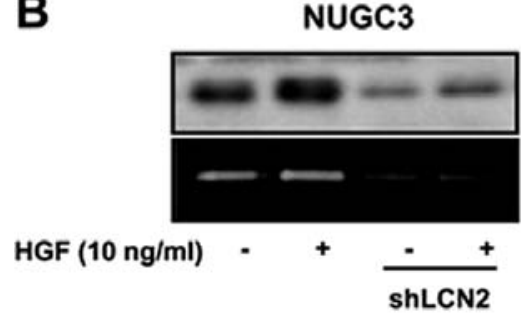

MKN28

LCN2
GAPDH

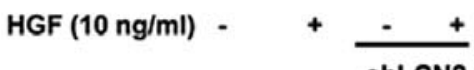

MKN28

MMP9

MMP9

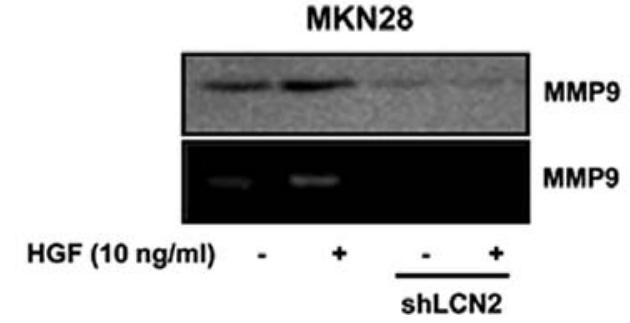

Figure 5. Effects of MMP9 in shLCN2 stable cells. Non-transfected control and LCN2-shRNA transfectioned cells were serum-starved and treated with/ without HGF $(10 \mathrm{ng} / \mathrm{ml})$ and harvested. (A) The LCN2 was confirmed by western blot analysis. (B) The MMP9 secreted in media was analyzed by western blotting and zymography. Representative data from 3 independent experiments are shown. MMP9, matrix metalloproteinase 9; LCN2, lipocalin 2; shRNA, short heparin RNA.

Effect of LY294002 on MMP9 expression. Some studies suggested that LCN2 was observed to stabilize MMP9 associated with tumor growth and metastasis. We tested whether MMP9 is also regulated by PI3-kinase-like LCN2. The cells were treated with PI3-kinase inhibitor (LY294002) and measured by western blotting and zymography. The results showed that HGF-mediated MMP9 was decreased with LY294002 (Fig. 4). We thusidentified that MMP9 is regulated by a PI3-kinase.

Effect of the LCN2 knockdown on HGF-mediated MMP9. To confirm that MMP9 is regulated by LCN2, the effect of LCN2 knockdown on HGF-mediated MMP9 was measured. We showed that LCN2 level was decreased in both LCN2 knockdown cell lines to identify the appropriate function of knockdown cells (Fig. 5A). We measured the effect of LCN2 knockdown of HGF-mediated MMP9 by western blotting. LCN2-shRNA cells showed a decreased level of HGF-mediated MMP9 (Fig. 5B).

Effect of $N F \kappa B$ on LCN2 expression. First we tested whether $\mathrm{NF} \kappa \mathrm{B}$ is mediated by $\mathrm{HGF}$ and regulated by a PI3-kinase. NFKB level was increased by HGF (Fig. 6A). Also,
HGF-mediated NFאB protein level was decreased with the PI3-kinase inhibitor LY294002 (Fig. 6B). To explore the regulation of $\mathrm{NF \kappa B}$ on $\mathrm{LCN} 2$, the cells were treated with $\mathrm{NF \kappa B}$ inhibitor (PDTC) and then the level of LCN2 was evaluated by western blotting. The HGF-mediated LCN2 protein level was decreased with treatment of PDTC in both NUGC3 and MNK28 cell lines (Fig. 6C). These results suggested that HGF-mediated LCN2 is regulated by NFאB.

Effect of LCN2 knockdown on HGF-mediated cell proliferation. To explore the effects of the LCN2 knockdown on HGF-mediated cell proliferation in gastric cancer cells, stable LCN2-shRNA cells were prepared by transfection of shRNA into NUGC-3 and MKN-28 cells. Knockdown of the LCN2shRNA stable cell was confirmed by RT-PCR. The control and LCN2-sh RNA cells were treated with HGF. After 72 h, we measured the cell proliferation by MTT assay. The data show that HGF-mediated cell proliferation was decreased in LCN2-sh RNA cells compared to control cells in both gastric cell lines $(\mathrm{P}<0.05)$ (Fig. 7).

Effect of the LCN2 knockdown on HGF-mediated cell invasion. To determine whether LCN2 has a role in cell invasion, 
A

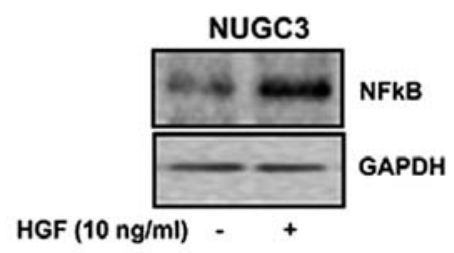

B

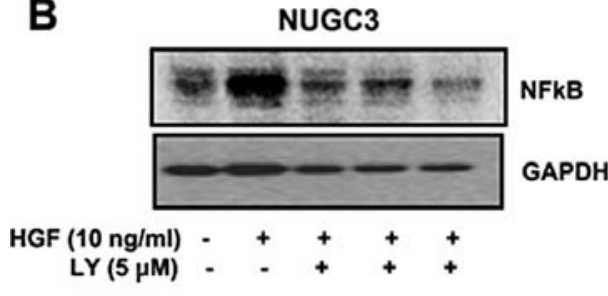

C

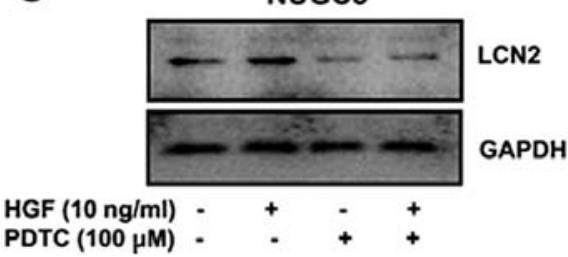

MKN28

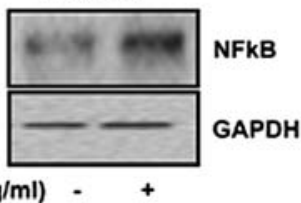

HGF $(10 \mathrm{ng} / \mathrm{ml})-\quad+$
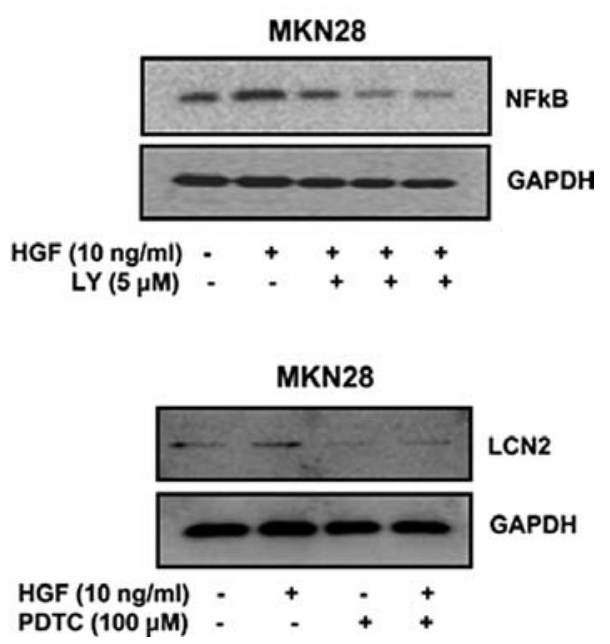

Figure 6. Effects of NFKB on LCN2 expression. Serum-starved cells were pretreated with LY at various doses for $45 \mathrm{~min}$ and then incubated with $10 \mathrm{ng} / \mathrm{ml}$ of HGF for $15 \mathrm{~min}$ and harvested. (A) The levels of expression of NFKB were confirmed by western blotting. Serum-starved cells were pretreated with/without PDTC $(100 \mu \mathrm{M})$ for $45 \mathrm{~min}$ and then incubated with $10 \mathrm{ng} / \mathrm{ml}$ of HGF for $15 \mathrm{~min}$, and harvested. (B and C) The levels of expression of LCN2 were confirmed by western blotting. Representative data from 3 independent experiments are shown. LCN2, lipocalin 2; HGF, hepatocyte growth factor; PDTC, pyrrolidine dithiocarbamate.
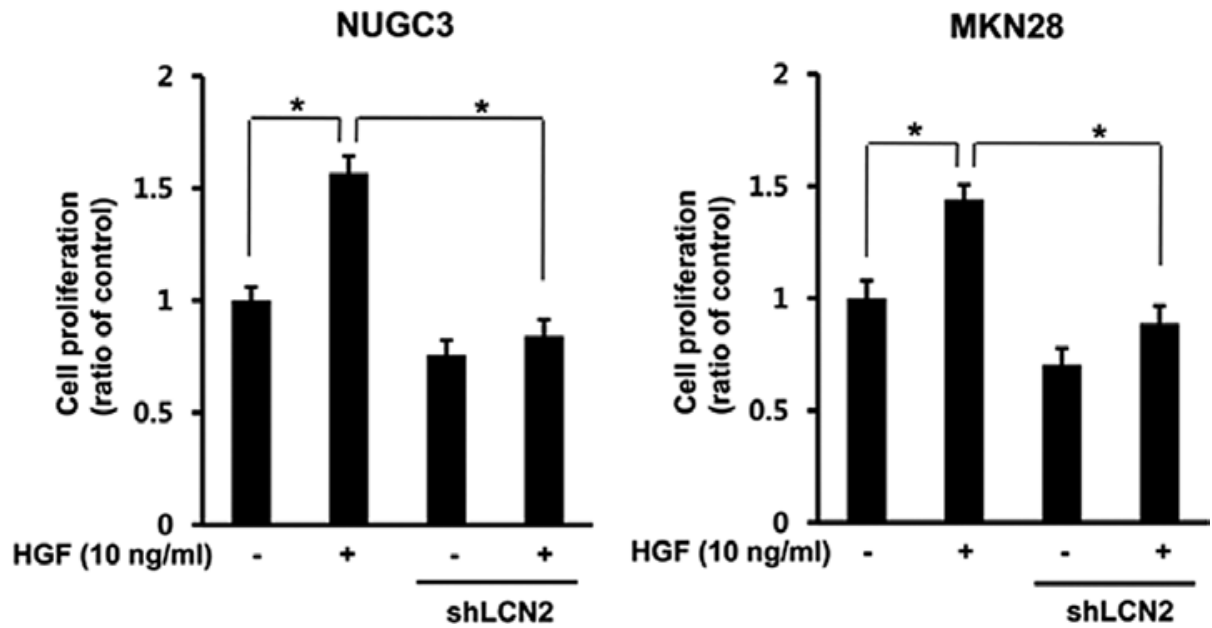

Figure 7. Effects of LCN2 on cell proliferation. Control (1,000/well) and stable LCN2-shRNA cells were seeded in 96-well plates with DMEM media supplemented with 5\% FBS and incubated for $24 \mathrm{~h}$. After serum-starvation for $24 \mathrm{~h}$, cell were treated with or without $10 \mathrm{ng} / \mathrm{ml}$ of HGF for $72 \mathrm{~h}$. Cell proliferation was measured by MTT assays and expressed as a percentage of HGF-untreated control cells. Values are the means \pm SD of 3 independent experiments performed in triplicate. ${ }^{*} \mathrm{P}<0.05$. LCN2, lipocalin 2 ; HGF, hepatocyte growth factor.

an in vitro invasion assay was performed using Matrigel migration chamber. The generated LCN2-shRNA was treated with HGF in NUGC3 and MKN28 cell lines. After $72 \mathrm{~h}$, HGF-mediated cell invasion was decreased in LCN2-shRNA in both cell lines $(\mathrm{P}<0.05)$ (Fig. 8).

Binding $N F \kappa B$ to the LCN2 promoter. To confirm that NFאB regulate transcriptional activity of $\mathrm{LCN} 2 \mathrm{mRNA}$ by binding to the LCN promoter, we investigated the promoter sequence of
LCN2 genes to establish the putative NFאB binding sequence using computer program for sequence analysis. One putative binding site was found within LCN2 promoter. NFאB binding site of LCN2 promoter sequence was located in the proximal promoter region of the transcriptional start site (Fig. 9A). To examine the function of NFאB binding site in the LCN2 promoter, LCN2 shRNA and control cells were treated with HGF and binding activity of $\mathrm{NF} \kappa \mathrm{B}$ to putative $\mathrm{NF} \kappa \mathrm{B}$ binding sites was measured by the ChIP assay. HGF enhanced $\mathrm{NF} \kappa \mathrm{B}$ 
NUGC3

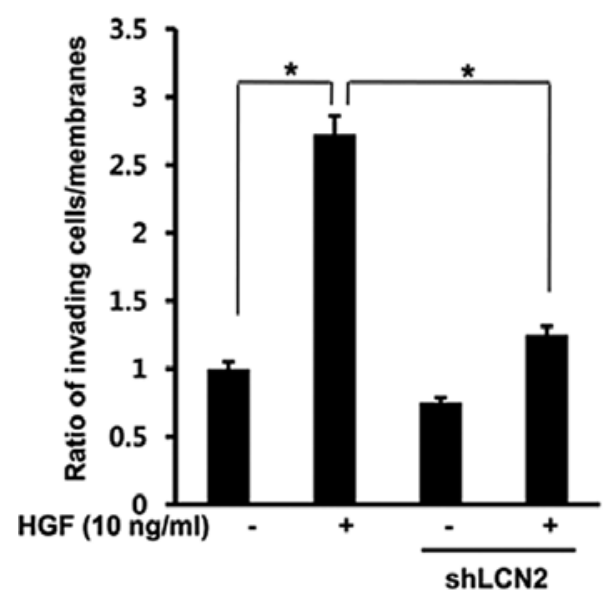

MKN28

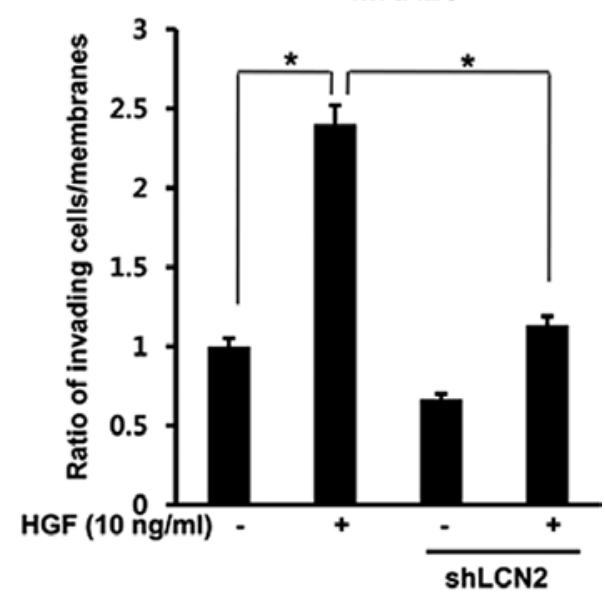

Figure 8. Effect of LCN2 on HGF-mediated cell invasion. Stable LCN2-shRNA and control cells were treated with/without $10 \mathrm{ng} / \mathrm{ml} \mathrm{HGF}$ for $48 \mathrm{~h}$. Cell invasion capacity was measured using the standard two chamber invasion assay with Matrigel migration chambers. Values are means \pm SD of 3 independent experiments. "P<0.05 LCN2, lipocalin 2; HGF, hepatocyte growth factor.

A

-340 gacagctcttccggctcacaggccaccggcccacatacagggcaatcagaagaaagaaacagcacaaggaaggc acagagggagtcgttgtccctgccagaggtgcagcactcc gggaatgtccctcactctccccgtccetctgtcttgccc aatcctgaccaggtgcagaaatcttgccaagtgtttccgcaggagttgctggcaattgcctcacattcctggecttggca aagaatgaatcaacccaccctagatcccataaatagggccacccaggtgagcctctcactcgccacctcctcttccac ccctgccaggcccagcagccaccacagcg

B
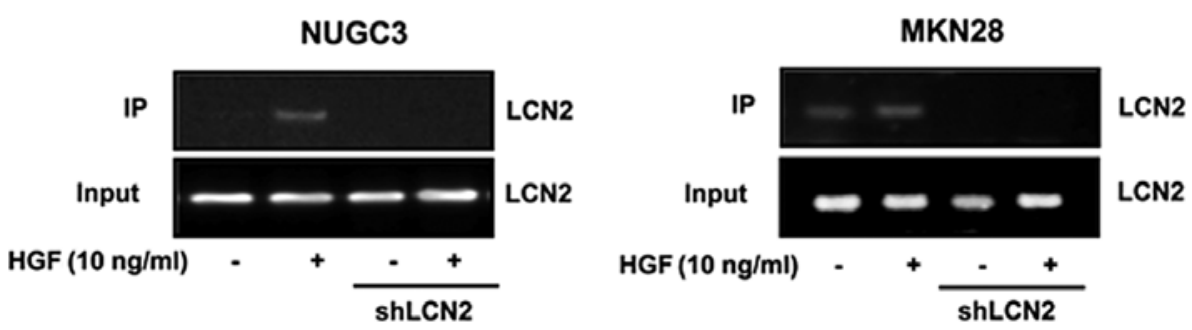

Figure 9. NFKB binds to the LCN2 promoter and is responsible for LCN2 upregulation by HGF. HGF enhances NFKB binding at the promoter sequences of LCN2. (A) Sequence of the proximal LCN2 promoters. The light grey marks the location of NFKB binding site. (B) ChIP assay results show the amplification of a fragment of the proximal LCN2 promoter containing the NFKB binding site. Immunoprecipitation was carried out using an anti-NFkB antibody. Representative data from 3 independent experiments are shown. LCN2, lipocalin 2; HGF, hepatocyte growth factor; ChIP, chromatin immunoprecipitation.

binding activity to the LCN2 promoter with strong activity in control cells, yet not in LCN2-shRNA cells (Fig. 9B).

\section{Discussion}

Gastric cancer is the most common malignant tumor and the second most common cause of cancer death worldwide $(15,16)$. The small reduction of gastric cancer mortality showed the need for further identification of targets or pathways that facilitate the proliferation and invasion of cancer.

MMP9 has been associated with cancer invasion by degradation of matrix in various tumor types. Recent studies reported that the high molecule LCN2/MMP9 complex which protect the MMP9 proteolytic degradation, was found in several types of cancer including breast, colon and gastric cancer $(12,13,17)$. This complex could perform remodeling of the ECM by degradation of an anchor protein of cell-to-cell adhesion $(4,18)$. Yet, there is little information concerning exact correlation between LCN2 and MMP9 and function of
LCN2 in tumorigenesis. Li et al suggested that LCN2 expression is upregulated by ErbB2 in the $\mathrm{NF} \kappa \mathrm{B}$ dependent pathway in breast cancer cells. They studied the association between ErbB2 and LCN2, not the association between LCN2 and MMP9 (19).

LCN2 is expressed in various epithelial and endothelial cells, fibroblasts and hepatocytes $(20,21)$. The level of LCN2 is enhanced in various types of cancer including stomach cancer (13), cholangiocarcinoma (10), breast (22), colon (17) and pancreatic cancer (23). It has been suggested that stimuli in the tumor microenvironment including hypoxia and inflammation induce LCN2 (24-27). Furthermore, LCN2 is associated with tumorigenesis and metastasis by enhancing gelatinase activity with LCN2 expression, which facilitates tumor growth by enhancing cell invasion of surrounding tissues in breast cancer (28).

It was shown that the complex of LCN2/MMP9 was enhanced in human gastric tumors and suggested that enhancing LCN2 level stimulates the formation of the complex 
with MMP9, which results in the maintenance of powerful proteinase action by protection of MMP9 autodegradation, and that high level of LCN2/MMP9 appears obviously correlated with overall survival of gastric cancer patients (13). On the contrary, the in vitro experiments suggested a protective role against cancer by showing that LCN2 induces the expression of E-cadherin, to diminish the invasiveness and metastasis in cancer cells (29). Another study reported that overexpression of LCN2 decreased cell invasion of colon and pancreatic cancer cells, suggesting the role of LCN2 as a suppressor of cancer metastasis (30).

We investigated whether HGF is associated with LCN2 and MMP9 in gastric cancer and identified the role of LCN2 upregulated by HGF associated with MMP9 in gastric cancer invasion and metastasis at molecular level. To identify whether LCN2 is associated with regulation of cell proliferation and invasion of metastatic characteristics, we knocked down the expression of LCN2 in NUGC3 and NKN28 cells using shRNA and evaluate in vitro cell proliferation, invasiveness and MMP9 activity. The present study showed that HGF upregulates LCN2 and MMP9, and MMP9 activity is upregulated by LCN2. Also, we identified that LCN2 is associated with cell proliferation and invasion by MTT and in vitro invasion assays in gastric cancer cell lines. Our data support the promotion of cancer metastasis by showing the suppression of in vitro invasiveness and proliferation of gastric cancer cell lines. These results are similar to the report of Nuntagowat $e t$ al, where LCN2 knockdown in cholangiocarcinoma is association with invasion and MMP activity. Yet, they reported the lack of effect in cell proliferation by LCN2 knockdown (10).

Furthermore, we found out the regulator pathway of LCN2 by identifying putative $\mathrm{NF} \kappa \mathrm{B}$ binding site in $\mathrm{LCN} 2$ promoter and confirmed that $\mathrm{LCN} 2$ in gastric cancer cells is upregulated directly by rhe NFאB pathway. MMP9 was inhibited with the PI3-kinase inhibitor LY294002 treatment, HGF-mediated MMP9 is also regulated by PI3-kinase. Moreover, the present study suggested that both LCN2 and MMP9 are regulated by the NFkB pathway. Pathway experiments on the regulation of LCN2 and MMP9 are rare. Only one study reported that LCN2 is upregulated by ErbB2 through NFאB activation (19). The present study provide evidence concerning the regulator pathway in invasion and proliferation of gastric cancer cell lines by LCN2 and MMP9.

Based on these results, we confirmed the definite relationship between LCN2 and MM9 and the function of cell proliferation and invasion of $\mathrm{LCN} 2$ in gastric cancer cell lines. Therefore, LCN2 appear to have a possible role in tumorigenesis and tumor invasion associated with MMP9 through $\mathrm{NF}$ B pathway in gastric cancer. Our findings support a previous study which suggested that LCN2 level stimulates the formation of the complex with MMP9 with human gastric tumor tissue (13).

Nuntagowat et al showed that silencing of LCN2 expression induced a significant suppression of in vitro invasion which paralleled a reduction of the LCN2/MMP9 complex (10). Zhang et al reported that the activity of LCN2/ MMP9 complex correlated with the depth of esophageal cancer using gelatin zymography (31). The present study does not provide evidence whether LCN2 directly regulates MMP9 and which mechanism acts in making the complex
LCN2/MMP9 and we do not have evidence whether the complex LCN2/MMP9 also acts in cancer invasion and proliferation in gastric cancer. We only confirmed that LCN2 regulates MMP9, that expression of LCN2 increased in vitro invasiveness and proliferation of gastric cancer cell lines and that LCN2 and MMP9 is separately regulated by $\mathrm{NF \kappa B}$, which means that $\mathrm{NF \kappa B}$ pathway does not have direct connection between LCN2 and MMP9.

To clarify our findings, further experiments are warranted using in vivo a knockout mouse model with both LCN2 and MMP9 and it is necessary to study the relation of the levels LCN2/MMP9 complex in samples of gastric cancer patients and clinical parameters and survival of the patients. It would be useful to examine the role of the LCN2/MMP9 complex.

In conclusion, the present study demonstrated that the MMP9 activity was upregulated by LCN2, and both LCN2 and MMP9 are controlled by the NFKB pathway which results in progression and invasion of two gastric cancer cell lines. This pathway may serve as possible therapeutic target option and provide information for further identification of other targets in gastric cancer.

\section{Acknowledgements}

This study was supported by the 2014 Yeungnam University Research Grant.

\section{References}

1. Yang J and Moses MA: Lipocalin 2: A multifaceted modulator of human cancer. Cell Cycle 8: 2347-2352, 2009.

2. Xu S and Venge P: Lipocalins as biochemical markers of disease. Biochim Biophys Acta 1482: 298-307, 2000.

3. Alpízar-Alpízar W, Laerum OD, Illemann M, Ramírez JA, Arias A, Malespín-Bendaña W, Ramírez V, Lund LR, Borregaard N and Nielsen BS: Neutrophil gelatinase-associated lipocalin (NGAL/Lcn2) is upregulated in gastric mucosa infected with Helicobacter pylori. Virchows Arch 455: 225-233, 2009.

4. Yan L, Borregaard N, Kjeldsen L and Moses MA: The high molecular weight urinary matrix metalloproteinase (MMP) activity is a complex of gelatinase B/MMP-9 and neutrophil gelatinase-associated lipocalin (NGAL). Modulation of MMP-9 activity by NGAL. J Biol Chem 276: 37258-37265, 2001.

5. Tschesche H, Zölzer V, Triebel S and Bartsch S: The human neutrophil lipocalin supports the allosteric activation of matrix metalloproteinases. Eur J Biochem 268: 1918-1928, 2001.

6. Sier CF, Kubben FJ, Ganesh S, Heerding MM, Griffioen G, Hanemaaijer R, van Krieken JH, Lamers CB and Verspaget HW: Tissue levels of matrix metalloproteinases MMP-2 and MMP-9 are related to the overall survival of patients with gastric carcinoma. Br J Cancer 74: 413-417, 1996.

7. Kubben FJ, Sier CF, van Duijn W, Griffioen G, Hanemaaijer R, van de Velde CJ, van Krieken JH, Lamers CB and Verspaget HW: Matrix metalloproteinase-2 is a consistent prognostic factor in gastric cancer. Br J Cancer 94: 1035-1040, 2006.

8. Matsumura S, Oue N, Nakayama H, Kitadai Y, Yoshida K, Yamaguchi Y, Imai K, Nakachi K, Matsusaki K, Chayama K, et al: A single nucleotide polymorphism in the MMP-9 promoter affects tumor progression and invasive phenotype of gastric cancer. J Cancer Res Clin Oncol 131: 19-25, 2005.

9. Kjeldsen L, Johnsen AH, Sengel $\varnothing \mathrm{v} \mathrm{H}$ and Borregaard N: Isolation and primary structure of NGAL, a novel protein associated with human neutrophil gelatinase. J Biol Chem 268: 10425-10432, 1993.

10. Nuntagowat $C$, Leelawat $K$ and Tohtong R: NGAL knockdown by siRNA in human cholangiocarcinoma cells suppressed invasion by reducing NGAL/MMP-9 complex formation. Clin Exp Metastasis 27: 295-305, 2010. 
11. Fernández CA, Yan L, Louis G, Yang J, Kutok JL and Moses MA The matrix metalloproteinase-9/neutrophil gelatinase-associated lipocalin complex plays a role in breast tumor growth and is present in the urine of breast cancer patients. Clin Cancer Res 11: 5390-5395, 2005.

12. Leng X, Ding T, Lin H, Wang Y, Hu L, Hu J, Feig B, Zhang W, Pusztai L, Symmans WF, et al: Inhibition of lipocalin 2 impairs breast tumorigenesis and metastasis. Cancer Res 69: 8579-8584, 2009.

13. Kubben FJ, Sier CF, Hawinkels LJ, Tschesche H, van Duijn W, Zuidwijk K, van der Reijden JJ, Hanemaaijer R, Griffioen G, Lamers CB, et al: Clinical evidence for a protective role of lipocalin-2 against MMP-9 autodegradation and the impact for gastric cancer. Eur J Cancer 43: 1869-1876, 2007.

14. Yang SH, Kim JS, Oh TJ, Kim MS, Lee SW, Woo SK, Cho HS, Choi YH, Kim YH, Rha SY, et al: Genome-scale analysis of resveratrol-induced gene expression profile in human ovarian cancer cells using a cDNA microarray. Int J Oncol 22: 741-750, 2003.

15. Parkin DM, Bray FI and Devesa SS: Cancer burden in the year 2000. The global picture. Eur J Cancer 37 (Suppl 8): S4-S66, 2001.

16. Jemal A, Bray F, Center MM, Ferlay J, Ward E and Forman D: Global cancer statistics. CA Cancer J Clin 61: 69-90, 2011.

17. Nielsen BS, Borregaard N, Bundgaard JR, Timshel S, Sehested M and Kjeldsen L: Induction of NGAL synthesis in epithelial cells of human colorectal neoplasia and inflammatory bowel diseases. Gut 38: 414-420, 1996.

18. Rudd PM, Mattu TS, Masure S, Bratt T, Van den Steen PE, Wormald MR, Küster B, Harvey DJ, Borregaard N, Van Damme J, et al: Glycosylation of natural human neutrophil gelatinase $\mathrm{B}$ and neutrophil gelatinase B-associated lipocalin. Biochemistry 38: 13937-13950, 1999.

19. Li SH, Hawthorne VS, Neal CL, Sanghera S, Xu J, Yang J, Guo H, Steeg PS and Yu D: Upregulation of neutrophil gelatinaseassociated lipocalin by ErbB2 through nuclear factor-kappaB activation. Cancer Res 69: 9163-9168, 2009.

20. Liu Q and Nilsen-Hamilton M: Identification of a new acute phase protein. J Biol Chem 270: 22565-22570, 1995.

21. Liu Q, Nilsen-Hamilton M and Xiong S: Synergistic regulation of the acute phase protein SIP24/24p3 by glucocorticoid and proinflammatory cytokines. Sheng Li Xue Bao 55: 525-529, 2003.
22. Bauer M, Eickhoff JC, Gould MN, Mundhenke C, Maass N and Friedl A: Neutrophil gelatinase-associated lipocalin (NGAL) is a predictor of poor prognosis in human primary breast cancer. Breast Cancer Res Treat 108: 389-397, 2008.

23. Tong Z, Kunnumakkara AB, Wang $H$, Matsuo Y, Diagaradjane $P$, Harikumar KB, Ramachandran V, Sung B, Chakraborty A, Bresalier RS, et al: Neutrophil gelatinase-associated lipocalin: A novel suppressor of invasion and angiogenesis in pancreatic cancer. Cancer Res 68: 6100-6108, 2008.

24. Viau A, El Karoui K, Laouari D, Burtin M, Nguyen C, Mori K, Pillebout E, Berger T, Mak TW, Knebelmann B, et al: Lipocalin 2 is essential for chronic kidney disease progression in mice and humans. J Clin Invest 120: 4065-4076, 2010.

25. Jiang W, Constante $M$ and Santos MM: Anemia upregulates lipocalin 2 in the liver and serum. Blood Cells Mol Dis 41: $169-174,2008$

26. Greten FR, Eckmann L, Greten TF, Park JM, Li ZW, Egan LJ, Kagnoff MF and Karin M: IKKbeta links inflammation and tumorigenesis in a mouse model of colitis-associated cancer. Cell 118: 285-296, 2004.

27. Li C and Chan YR: Lipocalin 2 regulation and its complex role in inflammation and cancer. Cytokine 56: 435-441, 2011.

28. Leng X, Wu Y and Arlinghaus RB: Relationships of lipocalin 2 with breast tumorigenesis and metastasis. J Cell Physiol 226: 309-314, 2011.

29. Hanai J, Mammoto T, Seth P, Mori K, Karumanchi SA, Barasch J and Sukhatme VP: Lipocalin 2 diminishes invasiveness and metastasis of Ras-transformed cells. J Biol Chem 280: 13641-13647, 2005.

30. Lee HJ, Lee EK, Lee KJ, Hong SW, Yoon Y and Kim JS: Ectopic expression of neutrophil gelatinase-associated lipocalin suppresses the invasion and liver metastasis of colon cancer cells. Int J Cancer 118: 2490-2497, 2006.

31. Zhang H, Xu L, Xiao D, Xie J, Zeng H, Wang Z, Zhang X, Niu Y, Shen Z, Shen J, et al: Upregulation of neutrophil gelatinaseassociated lipocalin in oesophageal squamous cell carcinoma: Significant correlation with cell differentiation and tumour invasion. J Clin Pathol 60: 555-561, 2007. 